Article

\title{
Dual Specificity Phosphatase 6 Protects Neural Stem Cells from $\beta$-Amyloid-Induced Cytotoxicity through ERK1/2 Inactivation
}

\author{
Wang Liao ${ }^{1,2,+}$, Yuqiu Zheng ${ }^{2,+}$, Wenli Fang ${ }^{2}$, Shaowei Liao ${ }^{2}$, Ying Xiong ${ }^{2}, \mathrm{Yi} \mathrm{Li}^{2}$, \\ Songhua Xiao ${ }^{2}$, Xingcai Zhang ${ }^{3, *}$ and Jun Liu ${ }^{2, *}$ \\ 1 Department of Psychiatry, McLean Hospital, Harvard Medical School, Belmont, MA 02478, USA; \\ docliaowang@foxmail.com \\ 2 Guangdong Province Key Laboratory of Brain Function and Disease, Zhongshan School of Medicine, \\ Sun Yat-sen University, Guangzhou 510120, China; zhengyq6@mail2.sysu.edu.cn (Y.Z.); \\ fangw1@mail2.sysu.edu.cn (W.F.); liaoshaowei2015@163.com (S.L.); xyzjy09154013@163.com (Y.X.); \\ liyi_lynn@126.com (Y.L.); xiaosh2017@163.com (S.X.) \\ 3 John A Paulson School of Engineering and Applied Science, Harvard University, Cambridge, \\ MA 02138, USA \\ * Correspondence: xingcai@seas.harvard.edu (X.Z.); docliujun@hotmail.com (J.L.); \\ Tel.: +1-225-3041-387 (X.Z.); +86-136-0979-4537 (J.L.) \\ + The first two authors contributed equally to this work.
}

Received: 14 November 2018; Accepted: 11 December 2018; Published: 19 December 2018

\begin{abstract}
Alzheimer's disease (AD) is a devastating neurodegenerative disease with limited treatment options and no cure. Beta-amyloid $(\mathrm{A} \beta)$ is a hallmark of $\mathrm{AD}$ that has potent neurotoxicity in neural stem cells (NSCs). Dual specificity phosphatase 6 (DUSP6) is a member of the mitogen-activated protein kinases (MAPKs), which is involved in regulating various physiological and pathological processes. Whether DUSP6 has a protective effect on A $\beta$-induced NSC injury remains to be explored. C17.2 neural stem cells were transfected with DUSP6-overexpressed plasmid. NSCs with or without DUSP6 overexpression were administrated with A $\beta 25-35$ at various concentrations (i.e., 0, 2.5, $5 \mu \mathrm{M}$ ). DUSP6 expression after A $\beta$ treatment was detected by Real-Time Polymerase Chain Reaction (RT-PCR) and Western blot and cell vitality was examined by the CCK8 assay. The oxidative stress (intracellular reactive oxygen species (ROS) and malondialdehyde (MDA)), endoplasmic reticulum stress (ER calcium level) and mitochondrial dysfunction (cytochrome c homeostasis) were tested. The expression of $p$-ERK1/2 and ERK1/2 were assayed by Western blot. Our results showed that $\mathrm{A} \beta$ decreased the expression of DUSP6 in a dose-dependent manner. The overexpression of DUSP6 increased the cell vitality of NSCs after A $\beta$ treatment. Oxidative stress, ER stress, and mitochondrial dysfunction induced by A $\beta$ could be restored by DUSP6 overexpression. Additionally, the A $\beta$-induced ERK1/2 activation was reversed. In summary, DUSP6 might have a neuroprotective effect on $\mathrm{A} \beta$-induced cytotoxicity, probably via ERK1/2 activation.
\end{abstract}

Keywords: Alzheimer's disease; DUSP6; A $\beta$; ER stress; mitochondrial; ERK; oxidative stress

\section{Introduction}

Alzheimer's disease (AD) is the most prevalent cause of dementia and affects 1 in 10 people over 65 years of age [1]. Currently, there are no known drugs that are able to stop the progressive cognitive decline associated with AD. Additionally, no new drugs have been approved by the Food and Drug Administration (FDA) since 2003 [2]. However, neural stem cell (NSC) therapy brings new hope to $\mathrm{AD}$ treatment. Adult neurogenesis is a process that generates new neural cells, which could be a 
promising therapeutic approach for neurodegenerative disease [3]. However, NSCs are susceptible to physiological or pathological microenvironment change [4].

One of the hallmarks of $\mathrm{AD}$ is the extracellular accumulation of beta-amyloid $(\mathrm{A} \beta)$, which has potent neurotoxicity on the central nervous system [5]. Therefore, it is crucial to prevent NSCs from this neurotoxicity. Multiple studies have shown ways to protect NSCs against A $\beta$, like mitochondrial protein (sirtuin3) [6] and natural herbs (incensole acetate) [7]. Our previous study demonstrated that dual specificity phosphatase 6 (DUSP6), a member of the dual specificity protein phosphatase subfamily, had a protective property against glutamate-induced cytotoxicity in mouse hippocampal neurons [8]. However, there is no evidence concerning the effects of DUSP6 in A $\beta$-induced cytotoxicity. Interestingly, the protein level of DUSP6 was found to be decreased in AD brain lysates and DUSP6 knockdown increased the level of phospho-ERK to promote high levels of tau phosphorylation $[9,10]$. Prior results indicate that DUSP6 could be a treatment target for AD.

The occurrence of $\mathrm{AD}$ is a multifactorial pathological process with many risk factors involved [11]. $A \beta$ aggregation induces oxidative stress, and increased reactive oxygen species (ROS) facilitate $A \beta$ generation, which consequently exacerbates cell damage [12]. Mitochondrial dysfunction plays a vital role in the pathological process of AD due to the high energy demand of the central nervous system [13]. Additionally, AD is associated with endoplasmic reticulum stress, which is thought to trigger cell death under $A \beta$ exposure [14]. In the present study, we investigate the role of DUSP6 in $\mathrm{A} \beta$-induced cytotoxicity in NSCs and the underlying molecular mechanisms involving oxidative stress, mitochondrial dysfunction, and reticulum stress.

\section{Results}

\section{1. $\beta$-amyloid Treatment Reduced DUSP6 Expression at Different Concentrations}

To explore the effect of A $\beta$-induced cytotoxicity in NSCs, DUSP6 mRNA was measured by RT-PCR after being treated with A $\beta 25-35(0,2.5,5 \mu \mathrm{M})$ for $24 \mathrm{~h}$. As shown in Figure 1A, DUSP6 mRNA was significantly reduced after $\mathrm{A} \beta 25-35$ treatment at concentrations of both 2.5 and $5 \mu \mathrm{M}(p<0.01$, $n=3)$. Consistently, DUSP6 protein expression detected by Western blot assay showed a decrease in the A $\beta 25-35$-treated group $(5 \mu \mathrm{M})(p<0.01, n=3)$ (Figure 1B), indicating that DUSP6 might play an important role in $\mathrm{A} \beta$-induced cytotoxicity in NSCs.
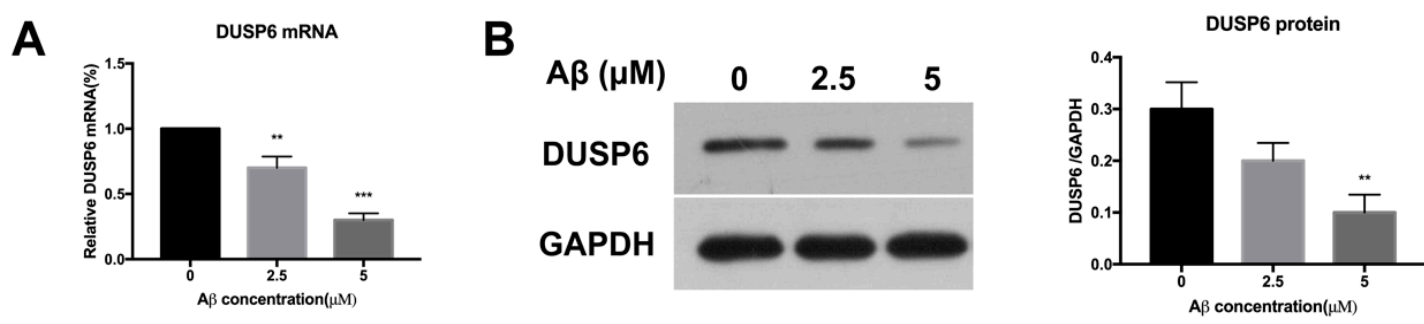

Figure 1. Beta amyloid (A $\beta$ )25-35 treatment reduced dual specificity phosphatase 6 (DUSP6) expression at different concentrations. (A) After treated with A $325-35(0,2.5,5 \mu \mathrm{M})$ for $24 \mathrm{~h}$, DUSP6 mRNA in neural stem cells (NSCs) was measured by RT-PCR; (B) DUSP6 protein was collected for Western blot assay. ${ }^{* *}: p<0.01,{ }^{* * *}: p<0.001$ vs. $0 \mu \mathrm{M} . n=3$. GAPDH: Glyceraldehyde-3-Phosphate Dehydrogenase.

\subsection{DUSP6 Prevented the beta-amyloid25-35-Induced Decrease in Neural Stem Cell Viability}

To further determine the role of DUSP6 in A $\beta$-induced cytotoxicity, DUSP6 overexpression plasmid was constructed and transfected into NSCs. Figure 2A shows that DUSP6 mRNA was overexpressed after being transfected with DUSP6 overexpression plasmid pcDNA-DUSP6 for $24 \mathrm{~h}$ $(p<0.001, n=3)$. In contrast, pcDNA3.0 empty vector transfection showed no effect on DUSP6 expression in NSCs $(p>0.05)$. 


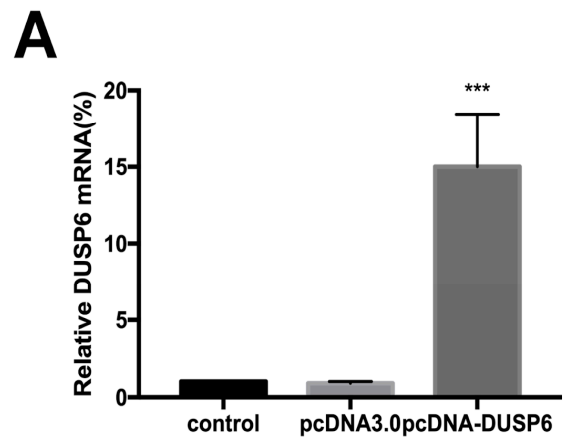

B

Figure 2. DUSP6 prevented the A $\beta$-triggered decrease in NSC viability. (A) DUSP6 mRNA was overexpressed after it was transfected with DUSP6-overexpressed plasmid pcDNA-DUSP6. pcDNA3.0 empty vector transfection showed no effect on DUSP6 expression in NSCs; (B) NSCs were either pre-transfected with DUSP6 overexpression plasmid or not transfected. Both groups were treated with $5 \mu \mathrm{M} \mathrm{A} \beta 25-35$ for $24 \mathrm{~h}$. Cell viability assessed by CCK8 assay showed no significant change in A $\beta$-treated NSC vitality after DUSP6 transfection. N.S.: $p>0.05,{ }^{* *}: p<0.01,{ }^{* * *}: p<0.001$ vs. control. *: $p<0.05$ vs. A $\beta$-treated group. $n=3$. N.S.: Not significant.

The non-transfected NSCs and DUSP6 plasmid-transfected NSCs were exposed to $5 \mu \mathrm{M}$ A $\beta 25-35$ for $24 \mathrm{~h}$. Non-transfected cells were regarded as a control, and cell viability was considered to be $100 \%$. Cell viability assessed by CCK8 assay showed a significant decrease in the A $\beta$-treated group $(p<0.01$, $n=3$ ) (Figure 2B). However, there was no significant change in the vitality of A $\beta$-treated NSCs after DUSP6 transfection $(p>0.05)$. Hence, our results indicate that DUSP6 could potentially prevent the effect of A $\beta 25-35$ on the viability of NSCs.

\subsection{DUSP6 Restored Reduced Intracellular Reactive Oxigen Species and Malondialdehyde Level in Neural Stem Cells After beta amyloid25-35 Treatment}

Some prior literature reported that oxidative stress plays a vital role in AD [15]. In the present study, we showed that both intracellular ROS and lipid peroxidation marker malondialdehyde (MDA) levels were increased after A $\beta 25-35$ treatment (Figure 3A, B) $(p<0.05, n=3)$. Notably, there was no difference between levels of intracellular ROS and MDA in the DUSP6-overexpressed group compared with that in the control group $(p>0.05)$. We observed a distinction between the A $\beta 25-35$-exposed group and the DUSP6-transfected group $(p<0.05, n=3)$, suggesting that the effect of $A \beta$ on intracellular ROS and MDA levels could be abrogated by DUSP6.
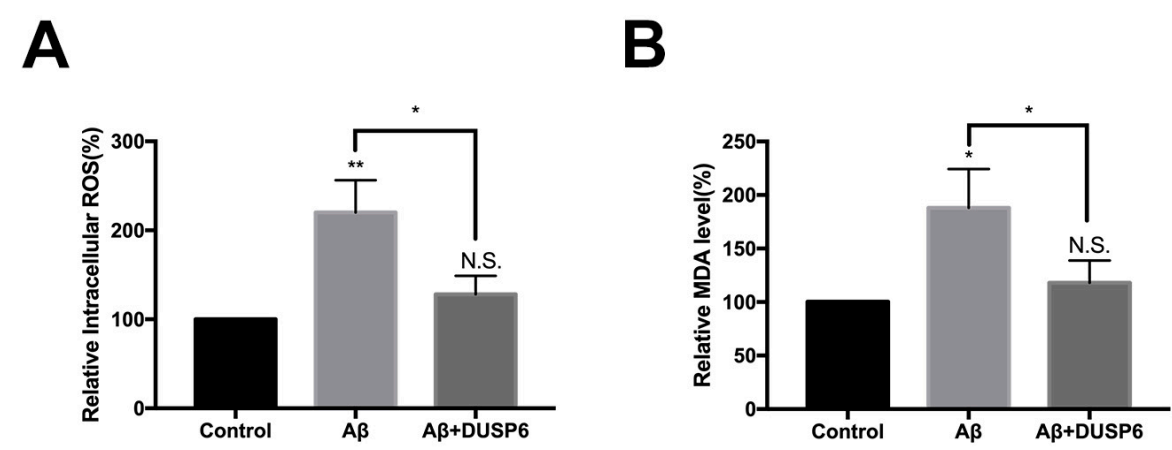

Figure 3. DUSP6 reduced A $\beta$-induced oxidative stress in NSCs. NSCs were either transfected with DUSP6 overexpression plasmid or not transfected. Both groups were treated with $5 \mu \mathrm{M} \mathrm{A} \beta 25-35$ for $24 \mathrm{~h}$ and then admitted to intracellular reactive oxygen species (ROS) (A) and lipid peroxidation marker malondialdehyde (MDA) assay (B). The values were normalized to the control group. N.S.: $p>0.05,{ }^{*}: p<0.05,{ }^{* *}: p<0.01$ vs. control. *: $p<0.05$ vs. A $\beta 25-35$ treated group. $n=3$. 


\subsection{DUSP6 Reversed A $\beta$-Induced Effect on ER Calcium and Mitochondrial Cytochrome $c$ Homeostasis in Neural Stem Cells}

Since $\mathrm{Ca}^{2+}$ can be released from the endoplasmic reticulum (ER) during stress [16], we assessed the content both in the ER and cytosol to determine the effect of A $\beta 25-35$ on NSCs after DUSP6 overexpression. As shown in Figure $4 \mathrm{~A}, \mathrm{~B}$, the levels of $\mathrm{Ca}^{2+}$ decreased significantly in the $\mathrm{ER}(p<0.05$, $n=3)$ while they increased in the cytosol after $\mathrm{A} \beta$ treatment $(p<0.01, n=3)$. Notably, the effect of $\mathrm{A} \beta$ on ER stress and cytosol $\mathrm{Ca}^{2+}$ homeostasis was reversed by DUSP6 $(p>0.05)$.

A

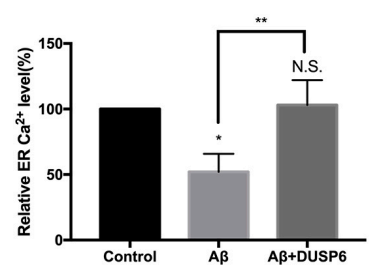

B

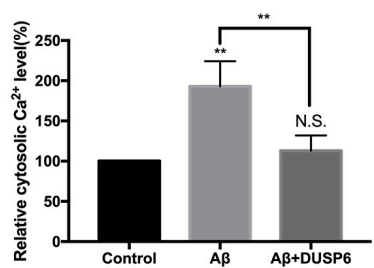

C

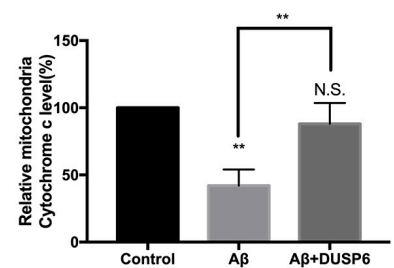

Figure 4. DUSP6 reversed A $\beta$-induced effect on $\mathrm{ER} \mathrm{Ca}^{2+}$ level and mitochondrial cytochrome $\mathrm{c}$ homeostasis in NSCs. NSCs were either pre-transfected with DUSP6 overexpression plasmid or not transfected. Both groups were treated with $5 \mu \mathrm{M} \mathrm{A} \beta 25-35$ for $24 \mathrm{~h}$. (A) Endoplasmic reticulum (ER) calcium was detected by fluorescent probe Fura-2/AM; (B) Cytosolic $\mathrm{Ca}^{2+}$ content in NSCs was measured with Indo-1/AM. (C) An enzyme-linked immunosorbent assay (ELISA) kit was adopted for the assay of cytochrome $\mathrm{c}$ in NSCs' mitochondria. N.S.: $p>0.05,{ }^{*}: p<0.05,{ }^{* *}: p<0.01$ vs. control. ${ }^{* *}: p<0.01$ vs. A $\beta$-treated group. $n=3$.

Alteration in mitochondria-released cytochrome $c$ is an indicator of cell death [17]. Hence, in this study, ELISA (Enzyme-Linked Immunosorbent Assay) was performed to detect cytochrome c in NSCs. Our results showed that while cytochrome $\mathrm{c}$ was reduced after A $\beta 25-35$ treatment $(p<0.01, n=3)$ (Figure 4C), this effect could be reversed by DUSP6 $(p>0.05, n=3)$.

\subsection{DUSP6 Regulated ERK1/2 Activation in Aß25-35-Exposed Neural Stem Cells}

Previous studies have reported that DUSP6 inactivated ERK1/2 [18]. Therefore, we assessed the expression of ERK1/2 activation by Western blot analysis after A $\beta 25-35$ exposure with or without DUSP6 overexpression. We found that the ratio of $p$-ERK/ERK was significantly up-regulated in A $325-35-e x p o s e d$ NSCs when compared with the control group. After DUSP6 transfection, $p$-ERK/ERK was significantly down-regulated when compared with that in A $325-35$ treated group ( $p<0.01, n=3$ ) (Figure 5). There was no significant change between the control and DUSP6-overexpressed groups ( $p>0.05$ ). This suggests that DUSP6 might protect NSCs from A $\beta 25-35$ induced cytotoxicity by modulating ERK1/2 signaling.
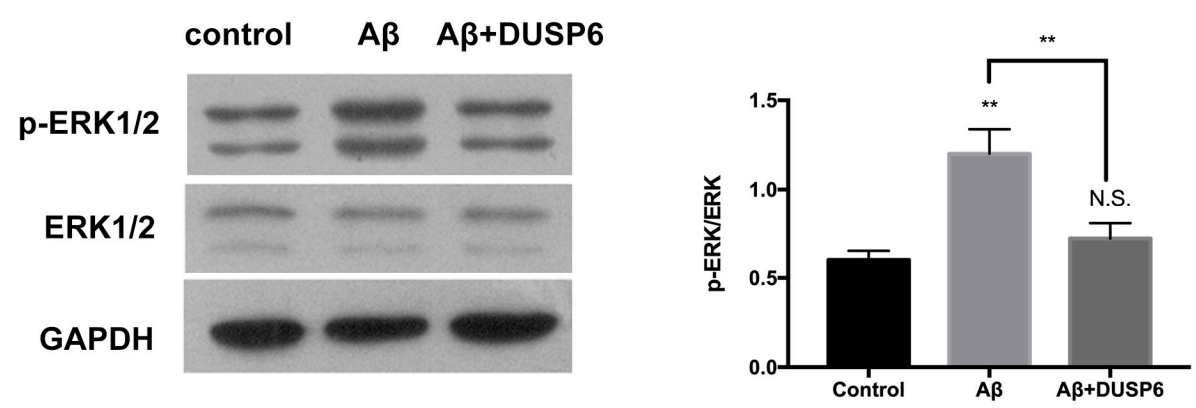

Figure 5. The effect of A $\beta 25-35$ and DUSP6 overexpression on ERK1/2 activation in NSCs. NSCs were transfected with the DUSP6 overexpression plasmid. After transfection for $24 \mathrm{~h}$, each group of cells was treated with A $\beta 25-35$ for $24 \mathrm{~h}$ and harvested for Western blotting. N.S.: $p>0.05, * *: p<0.01$ vs. control. ${ }^{* *}: p<0.01$ vs. the $\mathrm{A} \beta$-treated group. $n=3$. 


\section{Discussion}

Currently, there are two main types of Food and Drug Administration (FDA)-approved drugs available for the treatment of AD: cholinesterase inhibitors and N-Methyl-D-aspartate receptor (NMDAR) antagonists [19]. However, these drugs are not able to halt the progression of AD [20]. Immunotherapy targeting $A \beta$ or senile plaques have also been unsuccessful in reversing the cognitive function of $A D$ patients. Instead of cleaning $A \beta$, generating neural cells may be a new approach to $A D$ treatment [21].

There are several types of stem cells being considered as a therapeutic strategy for AD, such as mesenchymal stem cells (MSCs), NSCs, induced pluripotent stem cells (iPSCs), etc. [22]. Among them, autogenous neural stem cells are most useful, given their ethical, moral, and safety advantages [21]. Adult neurogenesis is a process by which new neurons are generated throughout life [23]. The adult-born neurons affect brain function; thus, their dysfunction correlates with AD progression [24]. However, NSCs are vulnerable to microenvironmental changes in the brain. Our previous research demonstrated that magnesium elevation promotes neural differentiation and suppresses glial differentiation in neural stem cells [25]. Additionally, NSCs are sensitive to neurotoxicity [7].

In the present study, we showed that A $\beta 25-35$ decreased the mRNA and protein expression of DUSP6 in C17.2 NSCs (Figure 1). Overexpression of DUSP6 restored cell vitality (Figure 2), oxidative stress (Figure 3), ER stress, and mitochondrial function (Figure 4), which were triggered by A $\beta 25-35$ exposure. The A $\beta 25-35$-induced ERK1/2 activation was also reversed by DUSP6 transfection (Figure 5). Collectively, DUSP6 may have a neuroprotective effect on A $\beta 25-35$-induced cytotoxicity in NSCs via ERK inactivation.

$\mathrm{AD}$ is characterized by two main pathological markers: senile plaques and neurofibrillary tangles [26]. The senile plaques are formed of $A \beta$, which is a protein with potent neurotoxicity to neural cells, especially NSCs [27]. Among the different kinds of A $\beta$ generated during AD pathogenesis, $A \beta 1-42$ is the most toxic, while $A \beta 1-40$ has the largest amount [20]. A $\beta 25-35$, a synthetic peptide based on $A \beta 1-40$ and $A \beta 1-42$, was reported to have the physical and biological properties of $A \beta$ without the need of aging before usage [28]. Our previous research demonstrated that A $\beta 25-35$ was capable of inducing autophagy in HT22 hippocampus cells, which involved the PI3K/AKT/mTOR/p70S6K pathway [29]. Hence, A $\beta 25-35$ was used in this study even though A $\beta 1-42$ might be more commonly used.

Recently, A $\beta 1-42$ was reported to affect the fate determination of NSCs [30]. It is assumed that $A \beta$ drives neural stem proliferation and neural differentiation of human NSCs at low concentrations but is neurotoxic at high concentrations (i.e., $1 \mu \mathrm{M}$ ) [31]. The mechanism could be related to the increased GSK $3 \beta$, induced by $A \beta 1-42$. The A $\beta 25-35$ concentrations used in the present study were $2.5 \mu \mathrm{M}$ and $5 \mu \mathrm{M}$, which are much higher than $1 \mu \mathrm{M}$. This might be why cytotoxicity was observed.

It is very important to not only understand the mechanism of $A \beta$ cytotoxicity but to find ways to protect NSCs from such cytotoxicity. According to previous literature, natural herbs such as incensole acetate have a neuroprotective effect on NSCs [7]. However, it would be more impactful to have autogenous biomolecules that can protect NSCs against $\mathrm{A} \beta$.

DUSP6 (MKP3, or Pyst1), a member of the mitogen-activated protein kinases (MAPKs), is involved in regulating various physiological and pathological processes [32]. Prior studies have shown the role of DUSP6 in cell growth, inflammation, proliferation, and stress responses [32]. In this study, we demonstrated that DUSP6 protected HT22 hippocampus cells and primary neurons from glutamate-induced cytotoxicity [8]. However, it is still uncertain as to whether DUSP6 has a protective effect on A $\beta$-induced NSCs.

DUSP6 is tightly regulated by stress at both transcriptional and post-transcriptional levels. Previous observations indicate that $\mathrm{A} \beta$ increases ERK phosphorylation [33], inducing CDK5 activation [34], which in turn causes neurodegeneration [35]. Furthermore, it has been shown that DUSP6 knockdown increases tau phosphorylation and decreases cell viability via ERK phosphorylation [9]. In fact, DUSP6 seems to be one of the downstream targets of miR-125b, which is increased in AD and the 
overexpression impairs learning and memory formation [9]. Of note, DUSP6 is down-regulated in post-mortem samples of AD and can directly dephosphorylate and inactivate ERK [36,37]. Moreover, the pattern of DUSP6 expression in vivo indicates a strong expression in CA1, which is one of the first areas affected in AD [38].

There are other dual-specificity phosphatases that have been reported to be involved in AD. For example, DUSP26 has been reported to stimulate A $\beta 42$ generation by promoting amyloid precursor protein axonal transport [39]. Sanchez-Mut et al. demonstrated that DUSP22 was reduced in AD patient sand mediated tau phosphorylation and CREB activation [40].

In the present study, we found that DUSP6 had a protective effect on A $\beta$-induced NSC injury, including oxidative stress, ER stress, and mitochondrial dysfunction. In this study, we examined ERK1/2 activation because DUSP6 has been reported to interact specifically with ERK1/2 at dual threonine and tyrosine residues [18]. The threonine-x-tyrosine TEY motifs of these residues lead to inactivation of ERK1/2, which has been demonstrated in both yeast and human cells [18].

The mechanism of interaction between DUSP6 and ERK1/2 is still unclear. Previous studies have suggested that DUSP6 overexpression de-phosphorylated ERK1/2 by blocking the MEK1-mediated GAL4-ELK1 activation [32]. DUSP6 was reported to interact with an apoptosis and autophagy-related protein BAG3. BAG3 encodes a multifunctional protein containing a BAG domain, which binds to heat shock protein (Hsp) 70. This might explain the protective effect of DUSP6 on mitochondrial function [41]. One of the main downstream targets of ERK signaling is E twenty-six (Ets) 2. Ets2 is a transcription factor that can bind to the DUSP6 promoter, which causes the up-regulation of DUSP6 [42]. An experiment on Ets2 transgenic mice showed that Ets2 also interacted with p53 promoter region, which is vital in the process of apoptosis [43]. This may be an explanation for the role of DUSP6 in A $\beta$-induced apoptosis. The mechanism of how A $\beta$ interacts with ERK1/2 also remains to be explored. One possible way that $A \beta$ interacts with ERK1/2 would be through receptors on the cell surface. It has been demonstrated that A $\beta 1-42$ bound to the formyl peptide receptor (FPR) on the cell membrane, enhancing the G protein-coupled receptor kinase 2 (GRK2) expression and leading to the phosphorylation of ERK1/2 at early stages [44].

In this study, we did not use specific ERK activators to mimic the A $\beta$ effect. Additionally, it would be beneficial if DUSP6 microRNA could be adopted to downregulate DUSP6 and further explore the mechanism. We are planning to construct a DUSP6-deficient mouse model to hybridize a APP/PS1 mouse in order to further explore its effect.

In this study, we showed that DUSP6 protected NSCs against A $\beta 25$-35-induced neurotoxicity, probably via ERK1/2 inactivation.

\section{Materials and Methods}

\subsection{Cell Culture and Treatment}

The C17.2 neural stem cell line has been widely used as an in vitro model for neurodegenerative diseases because of its capacity for self-renewal and differentiation [45]. In this study, the murine C17.2 cell line was adopted as a replacement. A C17.2 cell line (Sigma-Aldrich, St. Louis, MO, USA) was cultured in high-glucose Dulbecco's modified Eagle's medium (DMEM) supplemented with 10\% $(v / v)$ fetal bovine serum, 5\% (v/v) horse serum, $1 \%$ glutamine, $100 \mathrm{ng} / \mathrm{mL}$ streptomycin, and $100 \mathrm{units} / \mathrm{mL}$ penicillin [46]. All reagents were purchased from Gibco Thermo Fisher Scientific Inc. (Waltham, MA, USA).

The day before A $\beta 25-35$ treatment, cells were seeded onto a 35-mm dish at a density of $2 \times 10^{-5}$ cells per well. Different concentrations of Aß25-35 (2.5 and $5 \mu \mathrm{M})$ were added to the NSCs for $24 \mathrm{~h}$.

\subsection{CCK-8 Assay for Cell Viability}

The effects of A $325-35$ on NSCs viability were detected by CCK-8 assay (Dojin Laboratories, Kumamoto, Kyushu, Japan). according to the method we previously published [47]. Briefly, NSCs were 
cultured on a 96-well plate at a density of $1 \times 10^{4} /$ well for $24 \mathrm{~h}$ and administrated with A $\beta 25-35$ for another $24 \mathrm{~h}$. Then, the absorbance values were measured at $450 \mathrm{~nm}$ by a multifunctional microplate reader (SpectraMax M5, Sunnyvale, CA, USA) after being incubated at $37^{\circ} \mathrm{C}$ for $2 \mathrm{~h}$.

\subsection{Cell Transfection}

One day before transfection, NSCs were seeded onto a $35-\mathrm{mm}$ dish at a density of $2 \times 10^{5}$ cells per well. DUSP6 (NM_001946) overexpression plasmid was constructed and transfected as we described previously [8]. Primers used by us were as follows: $5^{\prime}$-cgcggatccgccaccATGATAGATACGCTCAGACCCGTGC- $3^{\prime}$ and $5^{\prime}$-ccgctcgagTCACGTAGACTGCAGGGAGTCCACC-3'. Plasmids were transfected using Lipofectamine 2000 according to the manufacturer's instructions (Invitrogen, Carlsbad, CA, USA).

\subsection{Quantitative Real-Time PCR (RT-PCR)}

NSCs were seeded onto six-well plates and received the indicated treatment. After A $\beta 25-35$ treatment for $24 \mathrm{~h}$, total RNA was extracted using Trizol reagent (Invitrogen, Carlsbad, CA, USA) according to the manufacturer's instructions. The primer sequences for DUSP6 and Glyceraldehyde-3-Phosphate Dehydrogenase (GAPDH) were as follows: DUSP6-F: 5'-GAGGGTAGCATAGGAATAGG-3', DUSP6-R: 5'-TCTCTTTGGCTCCACTATAC-3', GAPDH-F: 5'-GGCCTCCAAGGAGTAAGAAA-3', and GAPDH-R: $5^{\prime}$ GCCCCTCCTGTTATTATGG-3'. Reverse transcription and RT-PCR were performed in accordance with the protocol recommended by the manufacturers of SYBR Green qPCR SuperMix (Invitrogen). The relative expression of mRNA was assessed by the comparative $2^{-\Delta \Delta C T}$ method. GAPDH was used as an internal standard.

\subsection{Measurement of Oxidative Stress}

Intracellular reactive oxygen species was measured using fluorescent probe 2,7-dichlorofluorescein diacetate (DCFH-DA) [48]. Another indicator of oxidative stress, MDA, was detected with commercial kits as described previously [49].

\subsection{Detection of $\mathrm{Ca}^{2+}$ Levels}

$\mathrm{Ca}^{2+}$ levels were measured by $\mathrm{Ca}^{2+}$ imaging using the fluorescent probe Fura-2/AM (Thermo Fisher Scientific Inc.) as a routine procedure. Briefly, cells were washed twice and incubated with Fura-2/AM $(10 \mu \mathrm{M})$ for $30 \mathrm{~min}$. The fluorescence was measured using a microplate reader with an excitation filter of $340 \mathrm{~nm}$ and an emission filter of $380 \mathrm{~nm}$.

\subsection{Enzyme-Linked Immunosorbent Assay (ELISA)}

Cytochrome $\mathrm{c}$ of the mitochondria was measured using the cytochrome c ELISA kit (Thermo Fisher Scientific Inc.) as described previously. In brief, after being incubated on ice for $1 \mathrm{~h}$, cell lysates of NSCs were homogenized in a buffer and centrifuged for $5 \mathrm{~min}(700 \mathrm{~g})$. Then, mitochondrial fraction was collected from supernatants after being re-centrifuged for another $1 \mathrm{~h}$ at $8500 \times g$. Lastly, the absorbance of the samples was detected with a multifunctional microplate reader at $450 \mathrm{~nm}$ (SpectraMax M5, Sunnyvale, CA, USA).

\subsection{Western Blot Analysis}

Western blotting and semi-quantitative analyses were performed following previously described procedures [25]. In brief, proteins of NSCs were extracted with lysis buffer for $30 \mathrm{~min}$, followed by centrifugation at $14,000 \mathrm{rpm}$ for $15 \mathrm{~min}$ at $4{ }^{\circ} \mathrm{C}$ to obtain the supernatant for Western blot analysis. Primary antibodies and dilution rates used are as follows: $p$-ERK1/2 (1:1000, Cell Signaling Technology, Danvers, MA, USA), ERK1/2 (1:1000, Cell Signaling Technology (Danvers, MA, USA)), DUSP6 (1:500, Abcam, Cambridge, MA, USA). Secondary antibodies were purchased from Cell Signaling Technology 
Inc. Horseradish peroxidase-conjugated secondary antibodies were used, and the bands were fixed and visualized by an ECL advanced kit. GAPDH was utilized as an internal control for protein loading and transfer efficiency. Western blot assay results reported here are representative of at least three experiments. The quantification of protein expression was analyzed by Image J (National Institutes of Health, Bethesda, MD, USA).

\subsection{Statistical Analysis}

SPSS 16.0 for Windows (SPSS Inc., Chicago, IL, USA) was used to carry out the statistical analyses. Other statistical tests were conducted using one-way analysis of variance (ANOVA) and Student's $t$-test for comparisons between groups. The data were expressed as the mean $\pm \mathrm{SE}$, and differences were considered statistically significant at $p<0.05$.

Author Contributions: Conceptualization, X.Z. and J.L.; Funding acquisition, S.X., and J.L.; Methodology, W.F., S.L., Y.X., Y.L.; Writing-original draft, W.L. and Y.Z.; Writing-review \& editing, X.Z. and J.L.

Funding: This study was funded by Guangzhou Science and Technology Program key projects (J.L., 201604020100, S.X., 201803010013), Guangdong Science and Technology Program (J.L., 2017A020211017), Supporting Foundation of Sun Yat-sen University (J.L., 17ykjc17) and the National Nature Science Foundation of China (J.L., 81870836).

Acknowledgments: Special thanks go to Belinda Zhang at McLean Hospital, Harvard Medical School for editing this manuscript.

Conflicts of Interest: The authors declare no conflict of interest.

\section{References}

1. Cavedo, E.; Chiesa, P.A.; Houot, M.; Ferretti, M.T.; Grothe, M.J.; Teipel, S.J.; Lista, S.; Habert, M.O.; Potier, M.C.; Dubois, B.; et al. Sex differences in functional and molecular neuroimaging biomarkers of Alzheimer's disease in cognitively normal older adults with subjective memory complaints. Alzheimer's Dement. J. Alzheimer's Assoc. 2018, 14, 1204-1215. [CrossRef] [PubMed]

2. Cummings, J.; Lee, G.; Mortsdorf, T.; Ritter, A.; Zhong, K. Alzheimer's disease drug development pipeline: 2017. Alzheimer's Dement. 2017, 3, 367-384. [CrossRef] [PubMed]

3. Amemori, T.; Jendelova, P.; Ruzicka, J.; Urdzikova, L.M.; Sykova, E. Alzheimer's disease: Mechanism and approach to cell therapy. Int. J. Mol. Sci. 2015, 16, 26417-26451. [CrossRef] [PubMed]

4. Choi, S.H.; Bylykbashi, E.; Chatila, Z.K.; Lee, S.W.; Pulli, B.; Clemenson, G.D.; Kim, E.; Rompala, A.; Oram, M.K.; Asselin, C.; et al. Combined adult neurogenesis and BDNF mimic exercise effects on cognition in an Alzheimer's mouse model. Science 2018, 361, eaan8821. [CrossRef] [PubMed]

5. Tournier, B.B.; Tsartsalis, S.; Rigaud, D.; Fossey, C.; Cailly, T.; Fabis, F.; Pham, T.; Gregoire, M.C.; Kovari, E.; Moulin-Sallanon, M.; et al. TSPO and amyloid deposits in sub-regions of the hippocampus in the 3xTgAD mouse model of Alzheimer's disease. Neurobiol. Disease 2018, 121, 95-105. [CrossRef] [PubMed]

6. Voit, R.; Seiler, J.; Grummt, I. Cooperative action of Cdk1/cyclin B and SIRT1 is required for mitotic repression of rRNA synthesis. PLoS Geneti. 2015, 11, e1005246. [CrossRef] [PubMed]

7. El-Magd, M.A.; Khalifa, S.F.; Fa, A.A.; Badawy, A.A.; El-Shetry, E.S.; Dawood, L.M.; Alruwaili, M.M.; Alrawaili, H.A.; Risha, E.F.; El-Taweel, F.M.; et al. Incensole acetate prevents $\beta$-amyloid-induced neurotoxicity in human olfactory bulb neural stem cells. Biomed. Pharmacother. 2018, 105, 813-823. [CrossRef] [PubMed]

8. Huang, X.; Liao, W.; Huang, Y.; Jiang, M.; Chen, J.; Wang, M.; Lin, H.; Guan, S.; Liu, J. Neuroprotective effect of dual specificity phosphatase 6 against glutamate-induced cytotoxicity in mouse hippocampal neurons. Biomed. Pharmacother. 2017, 91, 385-392. [CrossRef] [PubMed]

9. Banzhaf-Strathmann, J.; Benito, E.; May, S.; Arzberger, T.; Tahirovic, S.; Kretzschmar, H.; Fischer, A.; Edbauer, D. MicroRNA-125b induces tau hyperphosphorylation and cognitive deficits in Alzheimer's disease. EMBO J. 2014, 33, 1667-1680. [CrossRef] [PubMed]

10. Bhore, N.; Wang, B.J.; Chen, Y.W.; Liao, Y.F. Critical roles of dual-specificity phosphatases in neuronal proteostasis and neurological diseases. Int. J. Mol. Sci. 2017, 18, 1963. [CrossRef] [PubMed]

11. Takeda, S. Progression of Alzheimer's disease, tau propagation, and its modifiable risk factors. Neurosci. Res. 2018, in press. [CrossRef] [PubMed] 
12. Manoharan, S.; Guillemin, G.J.; Abiramasundari, R.S.; Essa, M.M.; Akbar, M.; Akbar, M.D. The Role of reactive oxygen species in the pathogenesis of Alzheimer's Disease, Parkinson's Disease, and Huntington's Disease: A Mini Review. Oxid. Med. Cell. Longev. 2016, 2016, 8590578. [CrossRef] [PubMed]

13. Van Giau, V.; An, S.S.A.; Hulme, J.P. Mitochondrial therapeutic interventions in Alzheimer's disease. J. Neurol. Sci. 2018, 395, 62-70. [CrossRef] [PubMed]

14. Hashimoto, S.; Saido, T.C. Critical review: Involvement of endoplasmic reticulum stress in the Aetiology of Alzheimer's disease. Open Biol. 2018, 8, 180024. [CrossRef] [PubMed]

15. Jiang, T.; Sun, Q.; Chen, S. Oxidative stress: A major pathogenesis and potential therapeutic target of antioxidative agents in Parkinson's disease and Alzheimer's disease. Prog. Neurobiol. 2016, 147, 1-19. [CrossRef] [PubMed]

16. Zeeshan, H.M.; Lee, G.H.; Kim, H.R.; Chae, H.J. Endoplasmic reticulum stress and associated ROS. Int. J. Mol. Sci. 2016, 17, 327. [CrossRef] [PubMed]

17. Li, J.; Wang, Y.; Du, L.; Xu, C.; Cao, J.; Wang, Q.; Liu, Q.; Fan, F. Radiation-induced cytochrome c release and the neuroprotective effects of the pan-caspase inhibitor $\mathrm{z}$-VAD-fmk in the hypoglossal nucleus. Exp. Ther. Med. 2014, 7, 383-388. [CrossRef] [PubMed]

18. Arkell, R.S.; Dickinson, R.J.; Squires, M.; Hayat, S.; Keyse, S.M.; Cook, S.J. DUSP6/MKP-3 inactivates ERK1/2 but fails to bind and inactivate ERK5. Cell. Signal. 2008, 20, 836-843. [CrossRef] [PubMed]

19. Alzheimer's Association. 2016 Alzheimer's disease facts and figures. Alzheimer's Dement. J. Alzheimer's Assoc. 2016, 12, 459-509. [CrossRef]

20. Morris, G.P.; Clark, I.A.; Vissel, B. Questions concerning the role of amyloid- $\beta$ in the definition, aetiology and diagnosis of Alzheimer's disease. Acta Neuropathol. 2018, 136, 663-689. [CrossRef] [PubMed]

21. Sun, B.L.; Li, W.W.; Zhu, C.; Jin, W.S.; Zeng, F.; Liu, Y.H.; Bu, X.L.; Zhu, J.; Yao, X.Q.; Wang, Y.J. Clinical research on Alzheimer's Disease: Progress and perspectives. Neurosci. Bull. 2018, 34, 1111-1118. [CrossRef] [PubMed]

22. Sugaya, K.; Vaidya, M. Stem cell therapies for neurodegenerative diseases. Adv. Exp. Med. Biol. 2018, 1056, 61-84. [PubMed]

23. Berry, B.J.; Smith, A.S.T.; Young, J.E.; Mack, D.L. Advances and current challenges associated with the use of human induced pluripotent stem cells in modeling neurodegenerative disease. Cells Tissues Organs 2018, 1-19. [CrossRef] [PubMed]

24. Miyashita, T.; Oda, Y.; Horiuchi, J.; Yin, J.C.; Morimoto, T.; Saitoe, M. $\mathrm{Mg}^{2+}$ block of Drosophila NMDA receptors is required for long-term memory formation and CREB-dependent gene expression. Neuron 2012, 74, 887-898. [CrossRef] [PubMed]

25. Liao, W.; Jiang, M.; Li, M.; Jin, C.; Xiao, S.; Fan, S.; Fang, W.; Zheng, Y.; Liu, J. Magnesium Elevation Promotes Neuronal Differentiation While Suppressing Glial Differentiation of Primary Cultured Adult Mouse Neural Progenitor Cells through ERK/CREB Activation. Front. Neurosci. 2017, 11, 87. [CrossRef] [PubMed]

26. Hane, F.T.; Lee, B.Y.; Leonenko, Z. Recent progress in Alzheimer's disease research, Part 1: Pathology. J. Alzheimers Dis. 2017, 57, 1-28. [CrossRef] [PubMed]

27. Lin, C.H.; Nicol, C.J.B.; Cheng, Y.C.; Chen, S.J.; Yen, C.H.; Huang, R.N.; Chiang, M.C. Rosiglitazone rescues human neural stem cells from amyloid- $\beta$ induced ER stress via PPARgamma dependent signaling. Exp. Cell Res. 2018, 370, 312-321. [CrossRef] [PubMed]

28. Song, H.; Huang, L.P.; Li, Y.; Liu, C.; Wang, S.; Meng, W.; Wei, S.; Liu, X.P.; Gong, Y.; Yao, L.H. Neuroprotective effects of cordycepin inhibit A $\beta$-induced apoptosis in hippocampal neurons. Neurotoxicology 2018, 68, 73-80. [CrossRef] [PubMed]

29. Fan, S.; Zhang, B.; Luan, P.; Gu, B.; Wan, Q.; Huang, X.; Liao, W.; Liu, J. PI3K/AKT/mTOR/p70S6K pathway is involved in A $325-35-$ Induced autophagy. BioMed Res. Int. 2015, 2015, 161020. [CrossRef] [PubMed]

30. Coronel, R.; Bernabeu-Zornoza, A.; Palmer, C.; Muniz-Moreno, M.; Zambrano, A.; Cano, E.; Liste, I. Role of amyloid precursor protein (APP) and its derivatives in the biology and cell fate specification of neural stem cells. Mol. Neurobiol. 2018, 55, 7107-7117. [CrossRef] [PubMed]

31. Bernabeu-Zornoza, A.; Coronel, R.; Palmer, C.; Calero, M.; Martinez-Serrano, A.; Cano, E.; Zambrano, A.; Liste, I. A $\beta 42$ peptide promotes proliferation and gliogenesis in human neural stem cells. Mol. Neurobiol. 2018. [CrossRef] [PubMed] 
32. Ahmad, M.K.; Abdollah, N.A.; Shafie, N.H.; Yusof, N.M.; Razak, S.R.A. Dual-specificity phosphatase 6 (DUSP6): A review of its molecular characteristics and clinical relevance in cancer. Cancer Biol. Med. 2018, 15, 14-28. [PubMed]

33. Wang, Z.; Chen, Y.; Li, X.; Sultana, P.; Yin, M.; Wang, Z. Amyloid- $\beta 1-42$ dynamically regulates the migration of neural stem/progenitor cells via MAPK-ERK pathway. Chem.-Biol. Interact. 2018, 298, 96-103. [CrossRef] [PubMed]

34. Harada, T.; Morooka, T.; Ogawa, S.; Nishida, E. ERK induces p35, a neuron-specific activator of Cdk5, through induction of Egr1. Nat. Cell Biol. 2001, 3, 453-459. [CrossRef] [PubMed]

35. Giusti-Rodriguez, P.; Gao, J.; Graff, J.; Rei, D.; Soda, T.; Tsai, L.H. Synaptic deficits are rescued in the p25/Cdk5 model of neurodegeneration by the reduction of $\beta$-secretase (BACE1). J. Neurosci. 2011, 31, 15751-15756. [CrossRef] [PubMed]

36. Kim, Y.; Rice, A.E.; Denu, J.M. Intramolecular dephosphorylation of ERK by MKP3. Biochemistry 2003, 42, 15197-15207. [CrossRef] [PubMed]

37. Zhang, Z.; Kobayashi, S.; Borczuk, A.C.; Leidner, R.S.; Laframboise, T.; Levine, A.D.; Halmos, B. Dual specificity phosphatase 6 (DUSP6) is an ETS-regulated negative feedback mediator of oncogenic ERK signaling in lung cancer cells. Carcinogenesis 2010, 31, 577-586. [CrossRef] [PubMed]

38. Allen Brain Atlas. Available online: http://mouse.brain-map.org/experiment/show /79632277 (accessed on 1 December 2018).

39. Jung, S.; Nah, J.; Han, J.; Choi, S.G.; Kim, H.; Park, J.; Pyo, H.K.; Jung, Y.K. Dual-specificity phosphatase 26 (DUSP26) stimulates A $\beta 42$ generation by promoting amyloid precursor protein axonal transport during hypoxia. J. Neurochem. 2016, 137, 770-781. [CrossRef] [PubMed]

40. Sanchez-Mut, J.V.; Aso, E.; Heyn, H.; Matsuda, T.; Bock, C.; Ferrer, I.; Esteller, M. Promoter hypermethylation of the phosphatase DUSP22 mediates PKA-dependent TAU phosphorylation and CREB activation in Alzheimer's disease. Hippocampus 2014, 24, 363-368. [CrossRef] [PubMed]

41. Wang, Y.; Lin, J.; Chen, Q.Z.; Zhu, N.; Jiang, D.Q.; Li, M.X.; Wang, Y. Overexpression of mitochondrial Hsp75 protects neural stem cells against microglia-derived soluble factor-induced neurotoxicity by regulating mitochondrial permeability transition pore opening in vitro. Int. J. Mol. Med. 2015, 36, 1487-1496. [CrossRef] [PubMed]

42. Nunes-Xavier, C.E.; Tarrega, C.; Cejudo-Marin, R.; Frijhoff, J.; Sandin, A.; Ostman, A.; Pulido, R. Differential up-regulation of MAP kinase phosphatases MKP3/DUSP6 and DUSP5 by Ets2 and c-Jun converge in the control of the growth arrest versus proliferation response of MCF-7 breast cancer cells to phorbol ester. J. Biol. Chem. 2010, 285, 26417-26430. [CrossRef] [PubMed]

43. Wolvetang, E.J.; Wilson, T.J.; Sanij, E.; Busciglio, J.; Hatzistavrou, T.; Seth, A.; Hertzog, P.J.; Kola, I. ETS2 overexpression in transgenic models and in Down syndrome predisposes to apoptosis via the p53 pathway. Hum. Mol. Genet. 2003, 12, 247-255. [CrossRef] [PubMed]

44. Um, J.W.; Kaufman, A.C.; Kostylev, M.; Heiss, J.K.; Stagi, M.; Takahashi, H.; Kerrisk, M.E.; Vortmeyer, A.; Wisniewski, T.; Koleske, A.J.; et al. Metabotropic glutamate receptor 5 is a coreceptor for Alzheimer a $\beta$ oligomer bound to cellular prion protein. Neuron 2013, 79, 887-902. [CrossRef] [PubMed]

45. Luan, P.; Zhou, H.H.; Zhang, B.; Liu, A.M.; Yang, L.H.; Weng, X.L.; Tao, E.X.; Liu, J. Basic fibroblast growth factor protects C17.2 cells from radiation-induced injury through ERK1/2. CNS Neurosci. Ther. 2012, 18, 767-772. [CrossRef] [PubMed]

46. Oyarce, K.; Silva-Alvarez, C.; Ferrada, L.; Martinez, F.; Salazar, K.; Nualart, F. SVCT2 is expressed by cerebellar precursor cells, which differentiate into neurons in response to ascorbic acid. Mol. Neurobiol. 2018, 55, 1136-1149. [CrossRef] [PubMed]

47. Fan, D.; Li, J.; Zheng, B.; Hua, L.; Zuo, Z. Enriched environment attenuates surgery-induced impairment of learning, memory, and neurogenesis possibly by preserving BDNF expression. Mol. Neurobiol. 2016, 53, 344-354. [CrossRef] [PubMed] 
48. Zhao, Z.Y.; Luan, P.; Huang, S.X.; Xiao, S.H.; Zhao, J.; Zhang, B.; Gu, B.B.; Pi, R.B.; Liu, J. Edaravone protects $\mathrm{HT} 22$ neurons from $\mathrm{H}_{2} \mathrm{O}_{2}$-induced apoptosis by inhibiting the MAPK signaling pathway. CNS Neurosci. Ther. 2013, 19, 163-169. [CrossRef] [PubMed]

49. Fang, W.L.; Zhao, D.Q.; Wang, F.; Li, M.; Fan, S.N.; Liao, W.; Zheng, Y.Q.; Liao, S.W.; Xiao, S.H.; Luan, P.; et al. Neurotropin (R) alleviates hippocampal neuron damage through a HIF-1/MAPK pathway. Cns Neurosci. Ther. 2017, 23, 428-437. [CrossRef] [PubMed] 